\title{
Atmospheric boundary layer dynamics from balloon soundings worldwide: CLASS4GL v1.0
}

\author{
Hendrik Wouters ${ }^{1}$, Irina Y. Petrova ${ }^{1}$, Chiel C. van Heerwaarden ${ }^{2}$, Jordi Vilà-Guerau de Arellano ${ }^{2}$, \\ Adriaan J. Teuling ${ }^{3}$, Vicky Meulenberg ${ }^{2}$, Joseph A. Santanello ${ }^{4}$, and Diego G. Miralles ${ }^{1}$ \\ ${ }^{1}$ Laboratory of Hydrology and Water Management, Ghent University, Coupure Links 653, 9000 Ghent, Belgium \\ ${ }^{2}$ Meteorology and Air Quality Group, Wageningen University \& Research, P.O. Box 47, \\ 6700 AA Wageningen, the Netherlands \\ ${ }^{3}$ Hydrology and Quantitative Water Management Group, Wageningen University \& Research, P.O. Box 47, \\ 6700 AA Wageningen, the Netherlands \\ ${ }^{4}$ Hydrological Sciences Laboratory (617), Goddard Space Flight Center, National Aeronautics and Space Administration, \\ Greenbelt, MD, USA
}

Correspondence: Hendrik Wouters (hendrik.wouters@ugent.be)

Received: 28 January 2019 - Discussion started: 6 March 2019

Revised: 5 May 2019 - Accepted: 17 May 2019 - Published: 29 May 2019

\begin{abstract}
The coupling between soil, vegetation and atmosphere is thought to be crucial in the development and intensification of weather extremes, especially meteorological droughts, heat waves and severe storms. Therefore, understanding the evolution of the atmospheric boundary layer (ABL) and the role of land-atmosphere feedbacks is necessary for earlier warnings, better climate projection and timely societal adaptation. However, this understanding is hampered by the difficulties of attributing cause-effect relationships from complex coupled models and the irregular space-time distribution of in situ observations of the land-atmosphere system. As such, there is a need for simple deterministic appraisals that systematically discriminate land-atmosphere interactions from observed weather phenomena over large domains and climatological time spans. Here, we present a new interactive data platform to study the behavior of the ABL and land-atmosphere interactions based on worldwide weather balloon soundings and an ABL model. This software tool - referred to as CLASS4GL (http://class4gl.eu, last access: 27 May 2018) - is developed with the objectives of (a) mining appropriate global observational data from $\sim 15$ million weather balloon soundings since 1981 and combining them with satellite and reanalysis data and (b) constraining and initializing a numerical model of the daytime evolution of the ABL that serves as a tool to interpret these observations mechanistically and deterministi-
\end{abstract}

cally. As a result, it fully automizes extensive global model experiments to assess the effects of land and atmospheric conditions on the ABL evolution as observed in different climate regions around the world. The suitability of the set of observations, model formulations and global parameters employed by CLASS4GL is extensively validated. In most cases, the framework is able to realistically reproduce the observed daytime response of the mixed-layer height, potential temperature and specific humidity from the balloon soundings. In this extensive global validation exercise, a bias of $10.1 \mathrm{~m} \mathrm{~h}^{-1},-0.036 \mathrm{~K} \mathrm{~h}^{-1}$ and $0.06 \mathrm{~g} \mathrm{~kg}^{-1} \mathrm{~h}^{-1}$ is found for the morning-to-afternoon evolution of the mixed-layer height, potential temperature and specific humidity. The virtual tool is in continuous development and aims to foster a better process understanding of the drivers of the ABL evolution and their global distribution, particularly during the onset and amplification of weather extremes. Finally, it can also be used to scrutinize the representation of land-atmosphere feedbacks and ABL dynamics in Earth system models, numerical weather prediction models, atmospheric reanalysis and satellite retrievals, with the ultimate goal of improving local climate projections, providing earlier warning of extreme weather and fostering a more effective development of climate adaptation strategies. The tool can be easily downloaded via http://class4gl.eu (last access: 27 May 2018) and is open source. 


\section{Introduction}

Climate and weather phenomena are largely influenced by land surface processes and the characteristics of the landscape. The interactions between soil, vegetation and atmosphere are thought to be particularly important for the evolution of extreme weather events such as droughts, heat waves and convective thunderstorms (Santanello et al., 2018; Miralles et al., 2018; Seneviratne et al., 2010). The quantification of the drivers behind the extreme events is challenging, yet an understanding of the physical mechanisms underlying these events is highly relevant for earlier societal warning, better climate projection and timely adaptation (Sillmann et al., 2017). First efforts to quantify the relevance of land-atmosphere feedbacks date back to the late 20th century (e.g., Ek and Mahrt, 1994; Betts and Ball, 1995). However, substantial advancements have occurred in recent years after climate modeling initiatives such as the Global LandAtmosphere Coupling Experiment (GLACE; Koster et al., 2006; Guo et al., 2006; Berg et al., 2015), and observationbased studies under the umbrella of the Global Energy and Water Exchanges (GEWEX) Local Land-Atmosphere Coupling (LoCo) project (Roundy et al., 2013; Santanello et al., 2015, 2018; Tawfik et al., 2015). Recent studies have highlighted the importance of soil moisture and evaporation for the occurrence of afternoon rainstorms (Findell et al., 2011; Taylor et al., 2012; Guillod et al., 2015; Petrova et al., 2018), droughts (Roundy and Santanello, 2017; Teuling et al., 2013) and extreme heat events (Fischer et al., 2007; Miralles et al., 2014). Moreover, studies on anthropogenic land-cover change and land management - such as deforestation (Akkermans et al., 2013; Lejeune et al., 2014), irrigation (Thiery et al., 2017; Lawston et al., 2015), modified croplands (Seneviratne et al., 2010) and urban expansion (Wouters et al., 2017) - have demonstrated the profound influence of land conditions on local and regional climate and specifically on the occurrence of extreme weather.

However, assessing cause-effect relationships in observational and model studies of land-atmosphere interactions remains complex, given the cross-correlation of multiple climate variables without the need of implying causation, the bidirectional interactions within the system, the various scales of variability and autocorrelation of different elements, and the unavoidable confounding effect of unobserved causal variables (Miralles et al., 2018). Likewise, the many studies of land-atmosphere interactions based on the use of global or regional climate models are model dependent and only poorly constrained by observations (Orlowsky and Seneviratne, 2010; Davin et al., 2019), and the complexity of the Earth system models hampers the assessment of individual feedback processes. An intermediate compromise between statistical analysis of observations and complex climate model simulations could close this gap in process understanding. For example, mechanistic studies based on simpler models supported by observations have yielded new in- sights recently (Roundy et al., 2013; Zaitchik et al., 2013; Santanello et al., 2009). In particular, atmospheric boundary layer (ABL) models have been initialized and constrained with observations to simulate the atmospheric response to land surface conditions and the state of the free atmosphere; this way, the influence of turbulent heat fluxes, incoming radiation, subsidence, advection or entrainment can be easily quantified within certain ranges of uncertainty (Pietersen et al., 2015; Miralles et al., 2014; Ouwersloot et al., 2012; van Heerwaarden et al., 2009). For example, ABL models have been applied to investigate soil moisture and vegetation feedbacks during combined droughts and heat waves in Europe (Miralles et al., 2014), the different feedbacks on heat wave evolution over forests and grasslands (van Heerwaarden and Teuling, 2014), and the suppression of clouds by plants in a $\mathrm{CO}_{2}$-rich atmosphere (Vilà-Guerau de Arellano et al., 2012). The advantage of using these ABL bulk models is twofold: (a) unlike climate models, they can be routinely initialized and constrained by observations and are easily interpretable in terms of the interaction between variables; (b) unlike merely statistical analysis of observational data, they provide an unambiguous understanding of the deterministic links among the variables in the system. Yet, these mechanistic models require detailed observations describing the entire state or evolution of the soil, vegetation and atmosphere. Given this dependency, the previously mentioned process-based studies usually focus on one particular location only, for one or a few diurnal cycles at best. A generalization of the mechanistic outcomes of these process-based case studies to other climate regions or periods of extreme events may not always be justified. Overall, the atmospheric and land surface observations are irregular in time and space, which makes it very challenging to attribute the causes of meteorological variability.

Here, an open-source interactive data platform is presented based on the application of the Chemistry Land-surface Atmosphere Soil Slab model (CLASS; Vilà-Guerau de Arellano et al., 2015; van Heerwaarden et al., 2010) to balloon soundings worldwide. The platform, hereafter referred to as the CLASS4GL (CLASS model for GLobal studies), is designed to mine observations from the radio soundings, satellite remote-sensing observations, reanalysis data and surface data inventories to constrain and initialize the ABL model (CLASS). It automizes mass parallel simulations of the ABL and enables global sensitivity experiments. As a result, it is designed for studies that aim to foster a better understanding of the dynamics of ABL and the development of extreme weather, and it allows the attribution of changes in the state of the ABL to specific land and atmospheric conditions. A core goal of this study is to present this interactive data platform, including a summary description of the ABL model and the data mining procedure used to initialize and constrain model simulations (Sect. 2). Furthermore, the skill of the modeling framework to reproduce the daytime evolution of the ABL is evaluated against worldwide observations from specific field 
campaigns as well as operational balloon soundings (Sect. 3). Finally, a perspective is provided in which the potential of this framework to contribute to a better understanding of land-atmosphere interactions over different climates is discussed (Sect. 4).

\section{Data and methods}

The CLASS4GL platform is composed of three modules (see Fig. 1), namely an ABL model (CLASS), a data mining module and an interface module. The ABL model is used to simulate the ABL evolution and is described in detail in Sect. 2.1. It requires appropriate observations of the ABL for the initialization in the morning and for the validation in the afternoon. Meanwhile, the data mining module collects profile observations from soundings taken during research campaigns and operational activities since 1981. The intensive research campaigns offer continuous high-quality sounding profiles available for specific time periods and locations, while the operational weather balloon soundings offer more regular balloon launches at a vast amount of locations around the world but with intermittent and varying quality. The profile database is extensive, yet spatially and temporally sparse. Quality check tools have been applied to mine the profiles that are appropriate for the ABL model in the way described in Sect. 2.2. In order to further constrain and initialize ABL model simulations with surface conditions and larger-scale atmospheric variables, the data mining module also employs ancillary data from satellite remote sensing, reanalysis and survey inventories (Sect. 2.3). File formats are NetCDF and YaML to enable the easy adoption of any (upcoming) input datasets and the exchange of profiles, parameters and model experiments among users and a central database. Finally, the interface module provides the ability to easily perform multiple simulations of the diurnal ABL evolution in parallel, as well as batches of sensitivity experiments. Therefore, it enables the parallelization of multiple model simulations and offers multiprocessing support for both regular computer workstations as well as supercomputing infrastructure. The interface module also implements a range of tools for pre-and post-processing the sparse data pool of inputs and experiments and a data explorer with a graphical user interface. As a result, CLASS4GL automizes mechanistic assessments of the observed diurnal ABL behavior around the globe, and allows the exploration of local land-atmosphere feedbacks and the attribution of cause-effect relationships. A detailed description of the platform is provided in the next subsections. CLASS4GL is provided as an open-source Python library, it is conveyed under the GNU General Public License version 3 (GPLv3), and it can be easily downloaded via http://class4gl.eu (last access: 27 May 2018).

\subsection{ABL model: CLASS}

CLASS is a conceptual bulk model that uses a small set of differential equations to reproduce the evolution of the ABL's essential properties over diurnal time spans in response to surface and atmospheric forcings and feedbacks. The reason for choosing a bulk model is the low computational cost and the easy interpretation of the canonical ABL properties in view of extensive global experiments. However, we note that other models that allow for a more complex and explicit representation of the turbulent processes in the $\mathrm{ABL}$ - such as single column ABL models or large-eddy simulation models - may also be implemented.

CLASS is based on the original work by Tennekes (1973) and uses the thermodynamic equations of the ABL proposed by Tennekes and Driedonks (1981). The ABL is represented as a single model layer. The use of the mixed-layer equations implies that the turbulence and vertical gradients inside the mixed layer are not explicitly resolved, and the potential temperature $(\theta)$, specific humidity $(q)$ and wind components are assumed to be homogeneous within the mixed layer. This assumption tends to be supported by the efficient turbulent mixing under convective conditions (Bauer, 1908). At the top of the mixed layer, the entrainment of heat and moisture is parameterized by a jump of $\theta, q$ and wind components over an infinitesimally small height, which are initialized with a constant lapse rate with height in the overlying free atmosphere. Entrainment flux is calculated as a fixed fraction (0.2) of the buoyancy flux, to which one also adds the entrainment flux driven by shear. An important feature of the model is the possibility to represent the subsidence coupled to the entrainment process at the inversion zone (Vilà-Guerau de Arellano et al., 2015). Herein, the subsidence velocity is a function of the divergence of the mean horizontal wind and the evolving mixed-layer height. The surface-atmosphere turbulent exchanges for momentum, heat and moisture in the surface layer are calculated considering their aerodynamic resistances. These are calculated in an iterative way assuming constant values for aerodynamic roughness lengths, while applying correction factors for non-neutral stratification of the atmospheric surface-layer (Paulson, 1970) according to the Monin-Obukhov similarity theory (Monin and Obukhov, 1954). It should be kept in mind that more realistic profiles with explicit ABL gradients for temperature, humidity and wind speed - especially at the top (entrainment zone) and bottom (surface layer) of the mixed layer - are not yet considered by the model. In order to tackle these limitations and associated uncertainties, more research is needed, employing more realistic profiles. The surface energy balance at the land surface is solved using the Penman-Monteith equation (Monteith, 1965), and the heat and moisture transport in the soil is described using a two-layer force-restore model (Noilhan and Planton, 1989; Noilhan and Mahfouf, 1996) employing empirical relations for soil hydraulic properties of Clapp and Hornberger (1978). The amount of net radiation avail- 


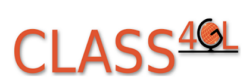

DATA

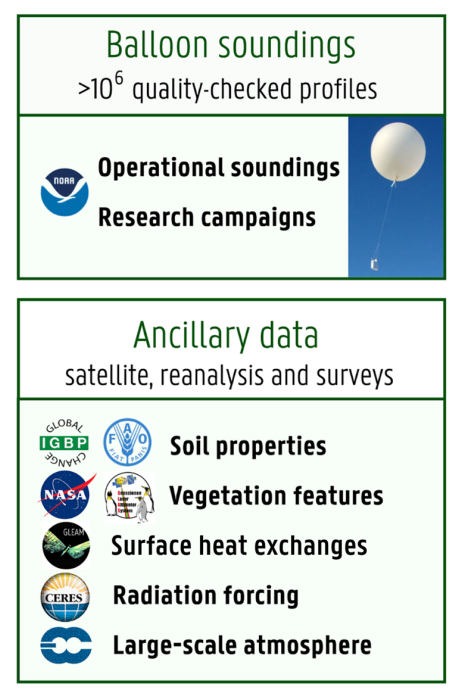

Interactive data platform to study the behavior of the atmospheric boundary layer
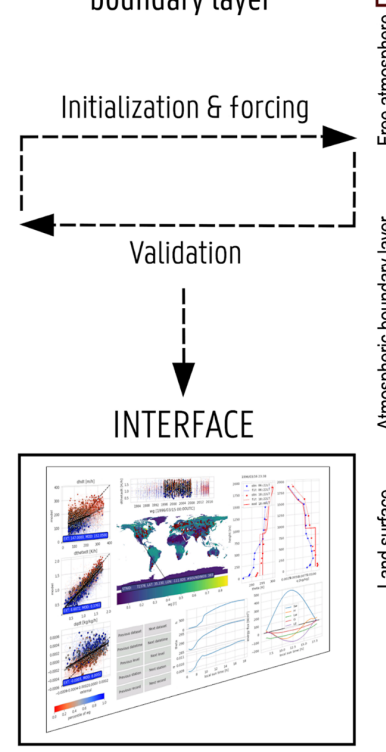

MODEL

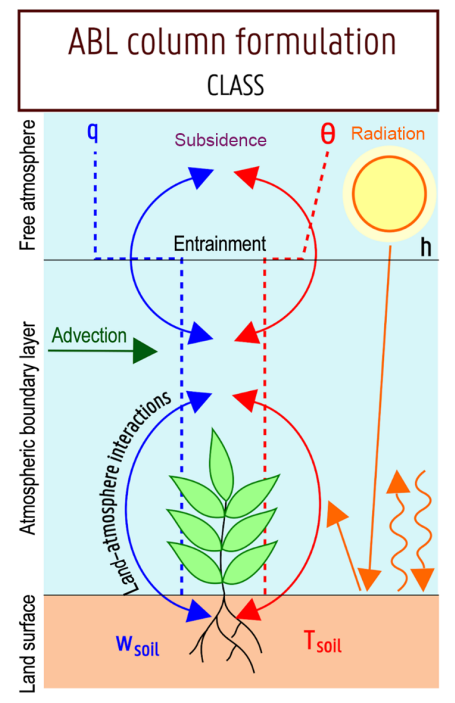

Figure 1. Schematic overview of the Chemistry Land-surface Atmosphere Soil Slab model for GLobal studies (CLASS4GL).

able for the sensible, latent and ground heat flux is calculated from the albedo, emissivity the incoming shortwave and long-wave radiation, the surface temperature, and the cloud cover. For the vegetation fraction, the transpiration response of vegetation to the atmospheric conditions considers the empirical stomatal resistance from Jarvis (1976) to be inversely proportional to the leaf area index and the plant water stress - assumed to be a linear function of the soil moisture deficit of the deep soil layer and also a function of the incoming shortwave radiation, the vapor pressure deficit and the air temperature. An analogous formulation is used for the resistance of the bare-soil fraction but considering it only as an inverse linear function to the soil moisture deficit of the shallow soil layer. More details and the explicit formulations of the coupled land-atmosphere system CLASS can be found in Vilà-Guerau de Arellano et al. (2015), van Heerwaarden and Teuling (2014) and van Heerwaarden et al. (2010).

In order to exploit the full database in CLASS4GL, the ABL model is upgraded with the following features:

- a representation of advection as an additional atmospheric dynamic forcing (see below).

- a representation of the upper-air atmospheric profile that also evolves according to the external large-scale dynamic forcing of advection and subsidence and as such accounts for varying (instead of constant) lapse rates of the capping inversion during the growth of the mixed layer.
- an implementation of alternative surface-layer transfer coefficients for momentum and heat Wouters et al. (2012), which account for additional non-neutral stability correction factors for the roughness sublayer (Ridder, 2009). The procedure uses a non-iterative approximation of the transcendental relation between the transfer coefficients and the Richardson bulk number, hence preserving numerical stability and decreasing the computational cost of CLASS.

- an iterative procedure to invert soil moisture conditions based on the match of the simulated evaporative fraction (EF) to satellite-based EF estimates. Details on this procedure can be found in Sect. 2.3 (Eq. 3).

To conclude this section, we elaborate the abovementioned CLASS model extension to consider advection as additional ABL dynamic forcing. It is assumed that both the mean vertical wind speed and also horizontal turbulent fluxes in the mixed layer are negligible, hence set to zero. As such, the laws of conservation of momentum, energy and atmospheric constituents in the mixed layer are given as follows:

$\frac{\partial \bar{\psi}}{\partial t}+\bar{u} \frac{\partial \bar{\psi}}{\partial x}+\bar{v} \frac{\partial \bar{\psi}}{\partial y}+\frac{\partial \overline{w^{\prime} \psi^{\prime}}}{\partial z}=\bar{S}_{\psi}$,

where $\psi$ is a generic variable $(\theta, q, u, v), u, v, w$ are the wind fields, the overbars indicate the Reynolds averages, $\psi^{\prime}$ indicates the fluctuation around the averages (note the difference from Eq. 2.5 of Vilà-Guerau de Arellano et al. (2015) 
because of the horizontal advection terms), and $\bar{S}_{\psi}$ represents the sum of the external forcings, sources and sinks of $\psi$. Integrating the last equation over the whole mixed-layer column in both the $x, y$ and $z$ direction yields the tendency of the bulk mixed-layer quantity (assuming no forcings, sources or sinks in the mixed layer):

$$
\frac{\partial\langle\psi\rangle}{\partial t}=\frac{1}{h}\left[\left\langle\left(w^{\prime} \psi^{\prime}\right)_{\mathrm{s}}\right\rangle-\left\langle\left(w^{\prime} \psi^{\prime}\right)_{\mathrm{e}}\right\rangle\right]-\left\langle\overline{\boldsymbol{U}} \cdot \nabla_{\mathbf{h o r}} \bar{\psi}\right\rangle,
$$

where $\left(w^{\prime} \psi^{\prime}\right)_{\mathrm{s}}$ is the vertical turbulent flux at the surface and $\left(w^{\prime} \psi^{\prime}\right)_{\mathrm{e}}$ is the entrainment flux at the mixed-layer height $(h)$, $l$ is the horizontal extent of the single column, \langle\rangle indicates the bulk (slab or mixed-layer) mean value of any field over the entire mixed-layer column, and $-\left\langle\overline{\boldsymbol{U}} \cdot \nabla_{\mathbf{h o r}} \bar{\psi}\right\rangle$ is the bulk horizontal advection for $\bar{\psi}$ in the mixed layer, which is obtained from external forcing fields.

\subsection{Automized balloon data mining}

Global data of weather balloon soundings are taken from the Integrated Global Radiosonde Archive (IGRA; Durre et al., 2006) which is maintained under the auspices of the National Oceanic and Atmospheric Administration (NOAA). The IGRA archive is routinely updated and currently includes more than 2700 stations covering major global climate regions. The CLASS4GL sounding database is additionally supplemented with data from intensive radiosonde campaigns from HUMPPA (Hyytiälä United Measurements on Particle Precursors in Air; Williams et al., 2011), BLLAST (Boundary Layer Late Afternoon and Sunset Turbulence; Pietersen et al., 2015) and GOAMAZON (Green Ocean Amazon; Martin et al., 2016) - see Table 1 and Fig. 2. Other sources of vertical profile data (e.g., from aircraft, satellites, other observation campaigns or long-term operational soundings) may be considered in future applications of the framework. As described above, CLASS requires morning sounding profiles for initialization and afternoon profiles for validation to enable a mechanistic interpretation of the diurnal ABL evolution.

All balloon sounding profiles ( $\sim 15$ million profiles) are preprocessed first by calculating the bulk mixed-layer properties: the mixed-layer height $(h)$ is assessed as the height at which the bulk Richardson number (RiB) exceeds a critical value $\left(\mathrm{RiB}_{\mathrm{c}}\right)$. We adopt the estimates for $\mathrm{RiB}_{\mathrm{c}}$ provided by Zhang et al. (2014): $\mathrm{RiB}_{\mathrm{c}}=0.24$ for strongly stable boundary layers, $\mathrm{RiB}_{\mathrm{c}}=0.31$ for weakly stable boundary layers and $\mathrm{RiB}_{\mathrm{c}}=0.39$ for unstable boundary layers. The uncertainty range of $h$ (used below) is determined from its interval corresponding to the $\mathrm{RiB}_{\mathrm{c}}$ range [0.24, 0.39], for which the interval is further extended to the nearest sounding records above and below. Second, the mixed-layer potential temperature $(\theta)$, specific humidity $(q)$, zonal wind $(u)$ and meridional wind $(v)$ are calculated as their average values recorded within the mixed layer. The capping inversion is estimated by a linear extrapolation of the two lowest sounding mea- surements above $h$, for which its lapse rate for potential temperature $\left(\gamma_{\theta}=\mathrm{d} \theta / \mathrm{d} z\right)$, specific humidity $\left(\gamma_{q}=\mathrm{d} q / \mathrm{d} z\right)$ and wind components $\left(\gamma_{u}=\mathrm{d} u / \mathrm{d} z\right.$ and $\left.\gamma_{v}=\mathrm{d} v / \mathrm{d} z\right)$ are calculated. The jump values at the $h$ for potential temperature $(\Delta \theta)$, specific humidity $(\Delta q)$ and wind components $(\Delta u$ and $\Delta v)$ are estimated from the difference between the values of the capping inversion at $h$ and the values within the mixed layer.

Afterwards, morning-afternoon profiles are selected that meet a series of selection criteria: the morning profiles, i.e., profiles before 12:00 local time, are selected first, and they amount to $\sim 6$ million profiles. Here, the selection of suitable morning soundings (and the subsequent afternoon soundings after 12:00 is based on the timing of these soundings (a): Morning (and afternoon) sounding profiles ideally should be acquired after sunrise and before sunset, respectively. However, routine sounding launches happen synchronously on a daily basis at 00:00 and 12:00 UTC, whereas launches at intermediate timings (03:00, 06:00, 09:00, 15:00 and 18:00 UTC) are rare. As a result, many launches, especially those at 00:00 UTC in Europe and Africa, often happen several hours before sunrise. Since the net exchanges near the surface for heat, moisture and radiation are generally low at the end of the night, the atmospheric profiles tend not to change dramatically before sunrise (unless the synoptic situation changes), often being representative of the time the mixed layer starts to emerge (van Stratum and Stevens, 2018). As such, in order to maintain a high number of soundings in our analyses, launch times within $3 \mathrm{~h}$ prior to sunrise are still allowed here. For these soundings, the ABL simulation starts at sunrise, assuming that the change in the atmospheric profile since the balloon launch time is negligible. Furthermore, (b) only those soundings are retained with more than seven measurements in the vertical below $3000 \mathrm{~m}$ ( $72 \%$ of the morning soundings), (c) for which the uncertainty of the mixed-layer height is lower than $150 \mathrm{~m}(26 \%$ of the morning soundings), (d) for which a well-mixed layer is observed (i.e., for which the root-mean square deviation of the temperature from the estimated mixed-layer average is lower than $1.5^{\circ} \mathrm{C}$; this criterion is met by $92 \%$ of the morning soundings). We also (e) set the morning lower temperature limit to $278 \mathrm{~K}$ in order to minimize the chance of freezing temperatures during the course of the simulations (this criterion is met by $70 \%$ of the morning soundings). The next criterion is that (f) an afternoon sounding can be found with the same criteria as the morning sounding except regarding the uncertainty of the mixed-layer height (which is met by $24 \%$ of the filtered morning soundings). Here, the afternoon radiosonde profile on the same day needs to occur between local noon and $1 \mathrm{~h}$ before sunset (defined as the time when the incoming shortwave radiation at the top of the atmosphere becomes zero), and at least $4 \mathrm{~h}$ after the model initialization by the morning sounding so that a sufficiently large model time span is considered. In case there are more than two soundings retained during a particular day which 


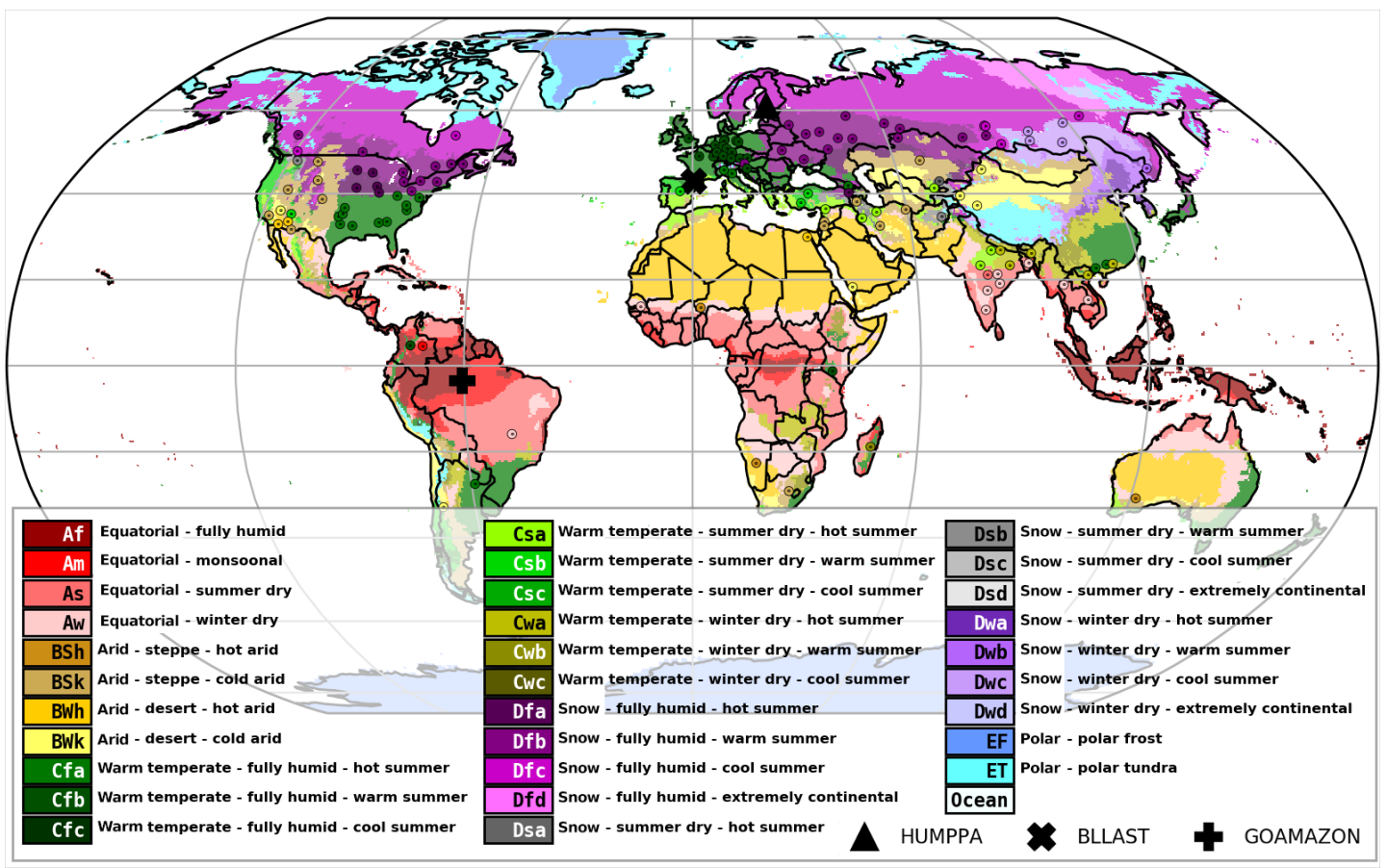

Figure 2. Distribution of the launch sites from the Integrated Global Radiosonde Archive (IGRA) retained after the profile quality selection procedure. The different climate classes are indicated with the colors according to the Köppen-Geiger climate classification. The markers indicate the locations of the three observation campaigns (i.e., HUMPPA, BLLAST and GOAMAZON). The profile quality selection is described and presented in Sect. 2.2.

occurs especially during the campaigns, the sounding closest to sunrise is taken for the initialization in the morning and the latest sounding for the validation in the afternoon, so that a sufficiently large model time span is considered. We also require that $(\mathrm{g})$ all external forcing parameters described in the next section are available for the simulation (which is met by $8.7 \%$ of the filtered sounding pairs). The above criteria lead to 21826 profile pairs from 134 stations. Finally, the current version of CLASS is only capable of representing growing mixed layers. Therefore, an observed mixed-layer growth of $40 \mathrm{~m} \mathrm{~h}^{-1}$ is considered as a lower limit (which is met by $85 \%$ of the profile pairs), which leads to 18385 profile pairs from 121 stations. For the three intensive observation campaigns, 22 out of 49 profiles are retained. An overview of the global distribution of the retained radiosondes and their corresponding climate regime is shown in Fig. 2. These requirements are flexible and may be reconsidered according to the intended application, since there is an obvious tradeoff between sounding quality and the amount of data being retained.

It should be noted that many sites have only a few days with sounding pairs that meet the selection criteria, and most often, there are only intermittent time series available. For applications that require continuous datasets, the extraction profiles from reanalysis data, satellite-based products or even Earth system models are also implemented in CLASS4GL.
This alternative to the use of sounding data holds great promise for spatially explicit climatological ABL studies and multi-annual trend assessments. ABL model simulations using continuous or gap-filled datasets may deviate from those using the observations. Hence, an additional validation is needed as soon as such datasets are employed, which should compare the gap-filled datasets with the observations and the error propagation in the ABL model simulations. Such an indepth evaluation against the available sounding pairs can be done using the present framework.

\subsection{Gridded ancillary data}

In addition to balloon observations, CLASS4GL uses gridded data of the land and large-scale atmospheric state to initialize and constrain ABL model simulations. These ancillary data aim at complementing the soundings and providing context regarding the land and atmospheric conditions for which the sounding measurements take place. In total, we use four satellite-based products, two survey datasets and one reanalysis to describe soil-vegetation conditions and large-scale atmospheric forcing. All input datasets and parameters are listed respectively in Tables 1 and 2, and details can be found in the next paragraphs.

Static datasets are used to describe initial soil properties and land-cover parameters, such as the fraction of land covered by vegetation and the surface albedo. The latter 
are based on the global vegetation continuous-fields product from the Moderate Resolution Imaging Spectroradiometer (MODIS MOD44B; Hansen et al., 2005). Wilting point, soil porosity, field capacity and critical soil moisture are derived from the database of Global Gridded Surfaces of Selected Soil Characteristics from the International GeosphereBiosphere Programme (IGBP-DIS, 2000). The Harmonized World Soil Database (HWSD; Nachtergaele et al., 2009) is used to provide soil classes. From this class, the Clapp and Hornberger parameters and the thermal parameters for the force-restore method are obtained via the look-up table in Noilhan and Planton (1989). The vegetation canopy height is determined from the Geoscience Laser Altimeter System (GLAS; Simard et al., 2011). Dynamic data of leaf area index (LAI) are taken from the Global Inventory Modeling and Mapping Studies (GIMMS) (Liu et al., 2012).

Initial surface and root-zone soil moisture values are inverted using the Global Land Evaporation Amsterdam Model (GLEAM) version 3.2a (Miralles et al., 2011; Martens et al., 2017) as a reference. In order to maximize the consistency between CLASS and GLEAM, the soil and vegetation ancillary data used by CLASS4GL, and described above, actually correspond to those used by the GLEAM v3.2a. It should be noted that CLASS and GLEAM have similar but not identical surface-vegetation-atmosphere transfer schemes; hence equivalent soil moisture levels may be associated with a differing EF. In order to minimize potential incompatibilities, CLASS4GL inverts soil moisture values by iteratively converging to the EF from GLEAM, instead of using the GLEAM root-zone soil moisture directly to initialize the ABL simulations. This iterative procedure is based on finding the zero of the following function:

$f(w)=\operatorname{EF}_{\text {CLASS }}(w)-\mathrm{EF}_{\text {GLEAM }}$,

where a unique soil moisture value $(w)$ is considered for the entire root zone in CLASS. In order to ensure convergence and reduce the number of iteration steps, two zero-finding algorithms have been combined, namely the discrete midpoint method and the bisection method (Burden et al., 2016). We note that this procedure is analogous to the one used by Miralles et al. (2014), in which CLASS was steered to match the Bowen ratios (instead of the EF) derived from GLEAM. However, for the results presented in Sect. 3, 1-hourly values of EF from recently released reanalysis dataset ERA5 (Copernicus Climate Change Service, C3S) are used instead of daily values from GLEAM, which provided a higher temporal resolution and better performance statistics. Since gridded and consistent satellite datasets of cloud properties, advection, subsidence and radiation are not available for the long time span, we also make use of reanalysis data from ERA-Interim (Dee et al., 2011). Moreover, reanalysis data are also used to initialize the soil temperature in the morning. As an alternative to the specification of cloud cover, one could also directly specify the radiation inputs based on ERA-Interim or measurements from the Clouds and Earth's
Radiant Energy System (CERES) onboard Terra and Aqua (Wielicki et al., 1996), which are available globally from the year 2001 onwards on a $1^{\circ}$ regular grid. Unless specified differently, the data are used in a dynamic manner in the CLASS simulations based on the temporal resolution specified in Table 1 . Since the lateral forcing for the calculation of advection is only available at a coarse spatial $\left(0.75^{\circ}\right)$ and temporal (6-hourly) resolution, a footprint of $1^{\circ}$ by $1^{\circ}$ is taken for the ABL column model - centered over the sounding location - over which average parameters of the different datasets are calculated for the model input. Finally, the CLASS4GL framework implements a flexible interface to any NetCDF files based on the Python or Xarray software libraries that a user may be interested in adding; hence alternative datasets can easily be adopted.

\section{Results and discussion}

The skill to replicate the evolution of the ABL as observed by the radiosondes is evaluated against the preprocessed and quality-controlled balloon soundings from (a) the three intensive research campaigns and (b) the global operational IGRA dataset. The evaluation is done by comparing the modeled daytime tendencies of the mixed-layer height $(\mathrm{d} h / \mathrm{d} t)$, potential temperature $(\mathrm{d} \theta / \mathrm{d} t)$ and specific humidity $(\mathrm{d} q / \mathrm{d} t)$ against the corresponding tendencies observed from the balloon sounding pairs. Observed and modeled tendencies represent the mean diurnal change from the morning sounding to the afternoon sounding. It should be noted that the local time of the morning and afternoon soundings changes given that the launch times are often at 00:00 and 12:00 UTC and that the boundary layer tendencies are not uniform over the course of the day. The resulting variety in the tendencies is taken into account in the simulations, since the model is initialized with the morning sounding while the initial solar local time in the model is set equal to the sounding launch. The same happens for the end of the simulation at the time of the afternoon sounding. Therefore, the expected tendency for each launch or site (depending on the local time window being considered in the computation of that tendency) is equivalent for observations and model simulations; hence any biases related to launching times between the two are avoided. The campaign observations provide an a priori higher standard than the operational balloons in terms of accuracy and resolution during the balloon ascent and in terms of daytime sampling. Hence, the evaluation against the 22 campaign soundings in our case serves as a control experiment of the model setup, initialization and forcing employed by CLASS4GL. In turn, validation of the model results against the 18k IGRA balloon sounding pairs serves as an overall evaluation of the suitability of CLASS4GL for the appraisal of the ABL behavior observed and associated landatmosphere feedbacks for different climate regimes. 

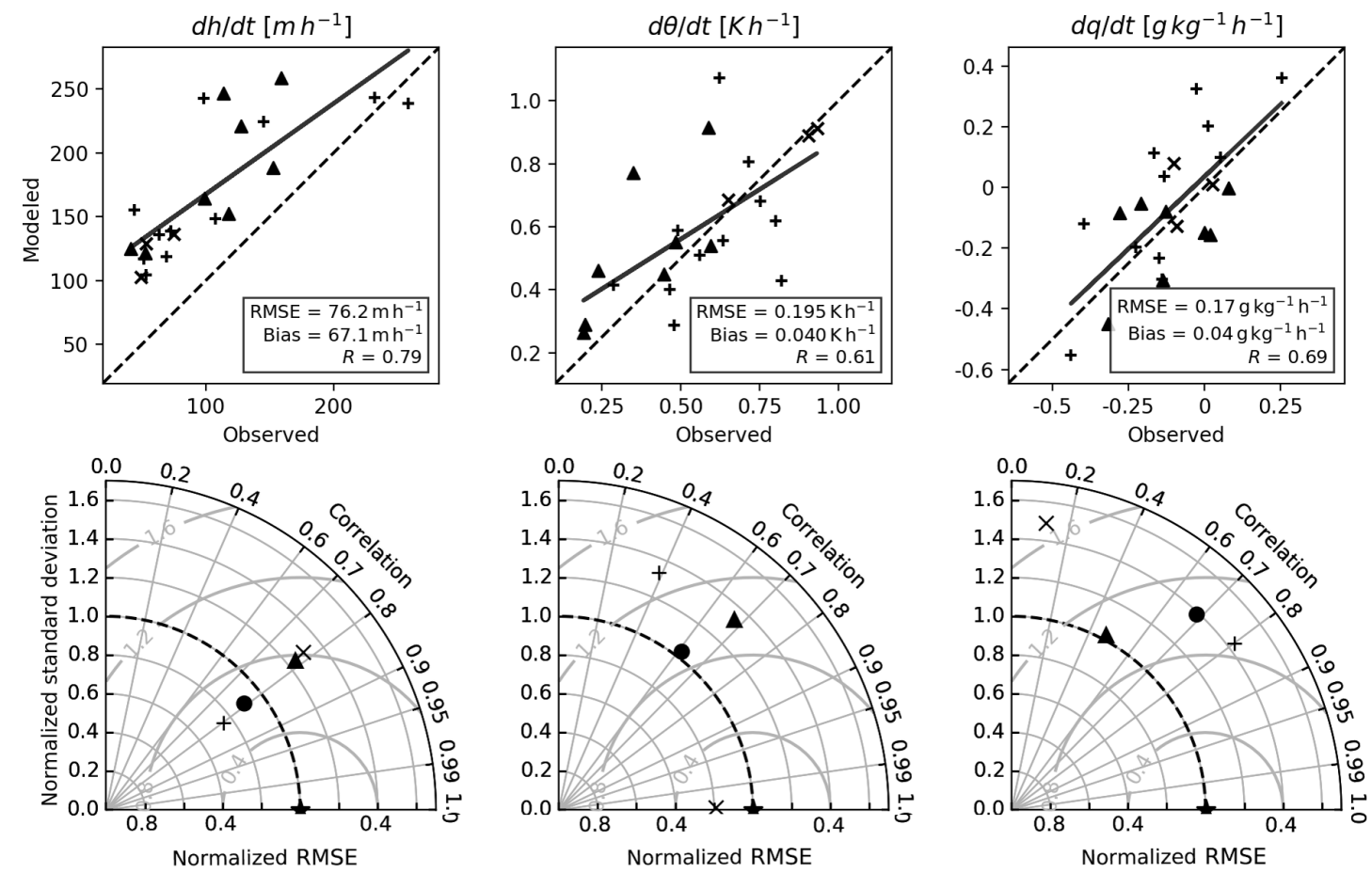

HUMPPA $\times$ BLLAST + GOAMAZON

All

Figure 3. Performance statistics of diurnal changes in mixed-layer properties (mixed-layer height: $\mathrm{d} h / \mathrm{d} t$; potential temperature: $\mathrm{d} \theta / \mathrm{d} t$; specific humidity: $\mathrm{d} q / \mathrm{d} t$ ) during the three intensive observation campaigns: HUMPPA, BLLAST and GOAMAZON. The $1: 1$ line is shown as a black dashed line.

The results of the model skill evaluation against the observations from the three intensive campaigns are summarized in Fig. 3. We find that the framework can reproduce the overall magnitude of the observed daytime tendencies $(\mathrm{d} h / \mathrm{d} t$, $\mathrm{d} \theta / \mathrm{d} t$ and $\mathrm{d} q / \mathrm{d} t)$, with a bias of $67.1 \mathrm{~m} \mathrm{~h}^{-1}, 0.04 \mathrm{~K} \mathrm{~h}^{-1}$ and $0.04 \mathrm{~g} \mathrm{~kg}^{-1}$, respectively. The model further reproduces the overall differential response among the campaign days and sites, with a Pearson correlation coefficient $(R)$ of 0.79 , 0.61 and 0.69 , for the three ABL tendencies. However, we could identify common model limitations over the three campaigns, particularly an overall (slight) positive bias in $\mathrm{d} h / \mathrm{d} t$ $(\mathrm{d} \theta / \mathrm{d} t$ and $\mathrm{d} q / \mathrm{d} t)$ and an under(over)estimation of its (their) variability as indicated with a normalized standard deviation different from 1 in the Taylor plots (Fig. 3). The bias is expected to have multiple origins, including the ABL model and its physical concepts, the forcing data (convergence/advection, evaporation bias, cloud cover...), model tuning parameters (such as the entrainment ratio), and errors in the sounding observations used to initialize and validate the model. All these possible error sources should be investigated in further development of CLASS4GL. The results of the three campaigns are useful as a first check of the model performance against high-quality observations. However, the sample size of $22 \mathrm{~d}$ over the three campaigns is too low to gain conclusive insights on whether these biases are of a sys- tematic nature. In this respect, the validation of model performance against the 36k IGRA soundings from 121 different stations in different climate regions provides a more reliable and comprehensive assessment.

The simulated diurnal ABL tendencies show a similar accuracy when evaluated against the global IGRA sounding archive, despite the fact that these operational sounding have a priori lower-quality standards than the campaign soundings; this applies to all three ABL tendencies shown in Fig. 4. Here, the magnitude of the bias is of the same order for the change in $\theta\left(-0.036 \mathrm{~K} \mathrm{~h}^{-1}\right)$ as for the intense observation campaigns but is now negative. The biases are smaller for $h$ $\left(10.1 \mathrm{~m} \mathrm{~h}^{-1}\right)$ compared to the campaigns and slightly larger for $q\left(0.06 \mathrm{~g} \mathrm{~kg}^{-1}\right)$. As for the research campaigns, the model is able to reproduce the variability among the different operational sounding days, with Pearson correlation coefficients of $0.53,0.82$ and 0.54 for the diurnal tendencies of $h, \theta$ and $q$, respectively. In addition, the overall modeled range in $\mathrm{d} h / \mathrm{d} t$, $\mathrm{d} \theta / \mathrm{d} t$ and $\mathrm{d} q / \mathrm{d} t$ agrees well with the observed range, for which the departure of the modeled (normalized) standard deviation from the observed (normalized) standard deviation of each tendency is below $22 \%$. This can be seen in the Taylor plots in Fig. 4, for which the centers of the open circles are between 0.78 and 1.22 of the normalized standard deviation. There is also a systematic underestimation of the variability 

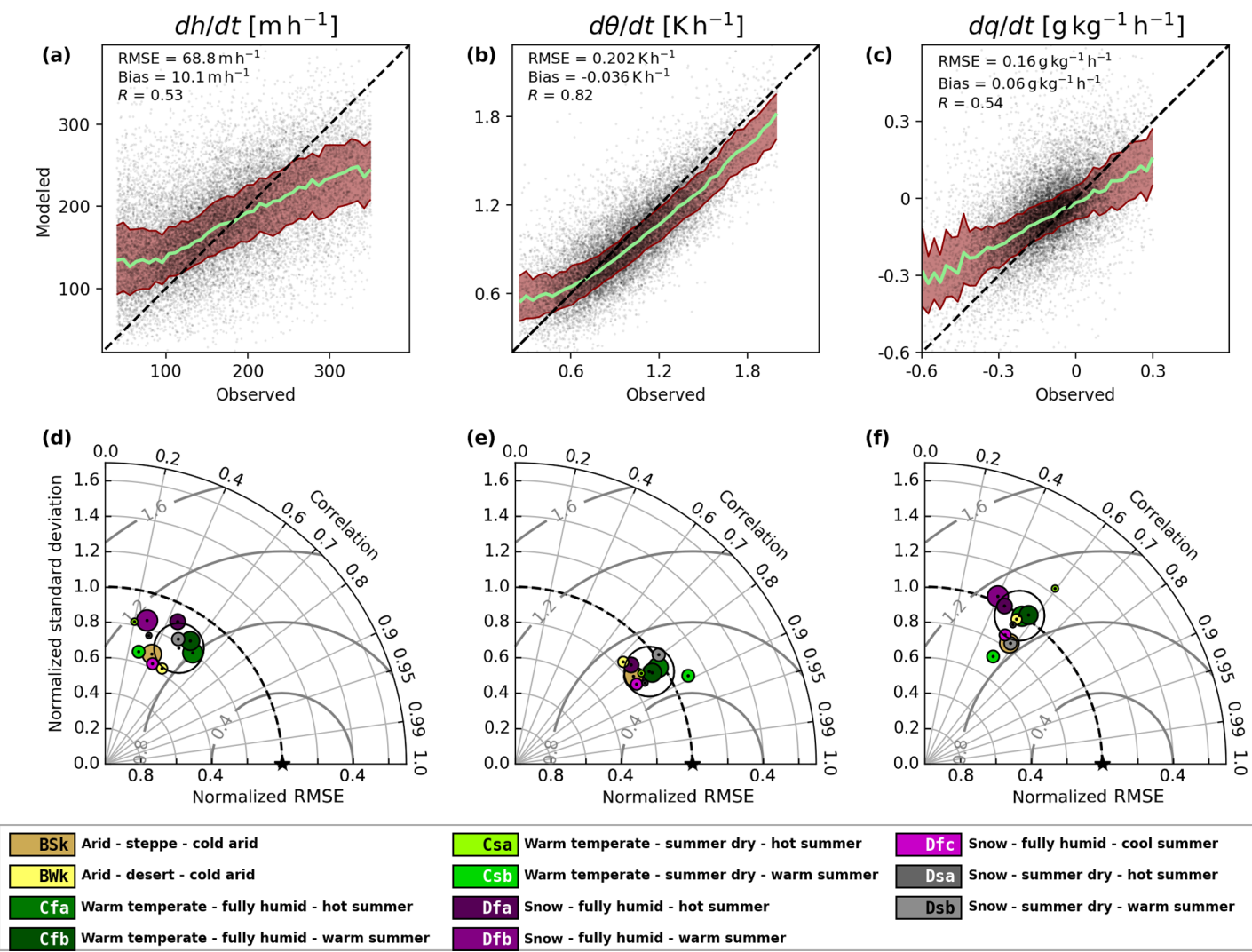

Figure 4. Model skill in reproducing diurnal changes in ABL properties. Shown are the tendencies of the mixed-layer height (d $h / \mathrm{d} t)$, potential temperature $(\mathrm{d} \theta / \mathrm{d} t)$ and specific humidity $(\mathrm{d} q / \mathrm{d} t)$, which are assessed by comparison of model simulations against the IGRA sounding data between 1981 and 2015. Panels (a)-(c) show modeled versus observed data points (gray) and the corresponding median (green) and interquartile range (red) of the model. The $1: 1$ line is shown as a black dashed line. The Taylor plots indicate the overall model performance as open circles and the performance corresponding to each Köppen-Geiger climate class as colored bullets. Only climate regimes with more than $>200$ soundings are illustrated. The size of the bullets is proportional to the amount of soundings for each particular climate class.

for $\mathrm{d} h / \mathrm{d} t, \mathrm{~d} \theta / \mathrm{d} t$ but not for $\mathrm{d} q / \mathrm{d} t$. The negative bias in the temperature tendency and the positive bias in the humidity tendency lead to an overall net heat bias of $114 \mathrm{~J} \mathrm{~kg}^{-1} \mathrm{~h}^{-1}$. Similar as for the results in the campaigns, it is expected that such global biases have multiple origins, including biases in the net radiation (which is calculated by the model by prescribing the cloud cover), underestimation of ground heat storage to the soil, the entrainment rates and/or the prescribed advection. Further research should investigate possible errors related to input datasets and validate them against independent data (e.g., the available CERES data could be used to evaluate the net radiation). Performance statistics vary slightly with the climate region under scope, e.g., with the correlations for $\mathrm{d} \theta / \mathrm{d} t$ ranging between 0.70 and $0.89 \mathrm{de}-$ pending on the climate regime. The highest model skill corresponds to warm temperate climates, while the lowest skill is found for humid regions, although the variability in model skill depends on the diagnosed variable and score metric. The similar model performance for the global IGRA archive (Fig. 4) compared to the intensive field campaigns (Fig. 3) gives us the confidence that the lower-quality standards of the operational measurements do not substantially hamper the framework performance, at least once the strict quality-based selection of radiosondes described in Sect. 2.2 is adopted.

The results in Figs. 3 and 4 suggest that the overall model skill in reproducing the diurnal cycle of $\theta$ is higher than the skill to reproduce the mixed-layer growth and the cycle of $q$. Validation results also indicate an overall underestimation of the $\theta$ increase and overestimation of the change in $q$ as the day progresses. At the same time, the high mixed-layer growths are underestimated. Additional sensitivity analyses aiming at lowering the EF suggest that these deficiencies could result from an overall overestimation of surface evaporation and an underestimation of surface sensible heat flux (not shown). This could relate in turn to errors in the EF input dataset or in the vegetation parameters (vegetation cover and LAI) that the determine the partitioning between soil evaporation and transpiration. Moreover, the underrepresentation of extremes (e.g., very dry or very wet conditions) could relate to the coarse resolution of the surface soil pa- 


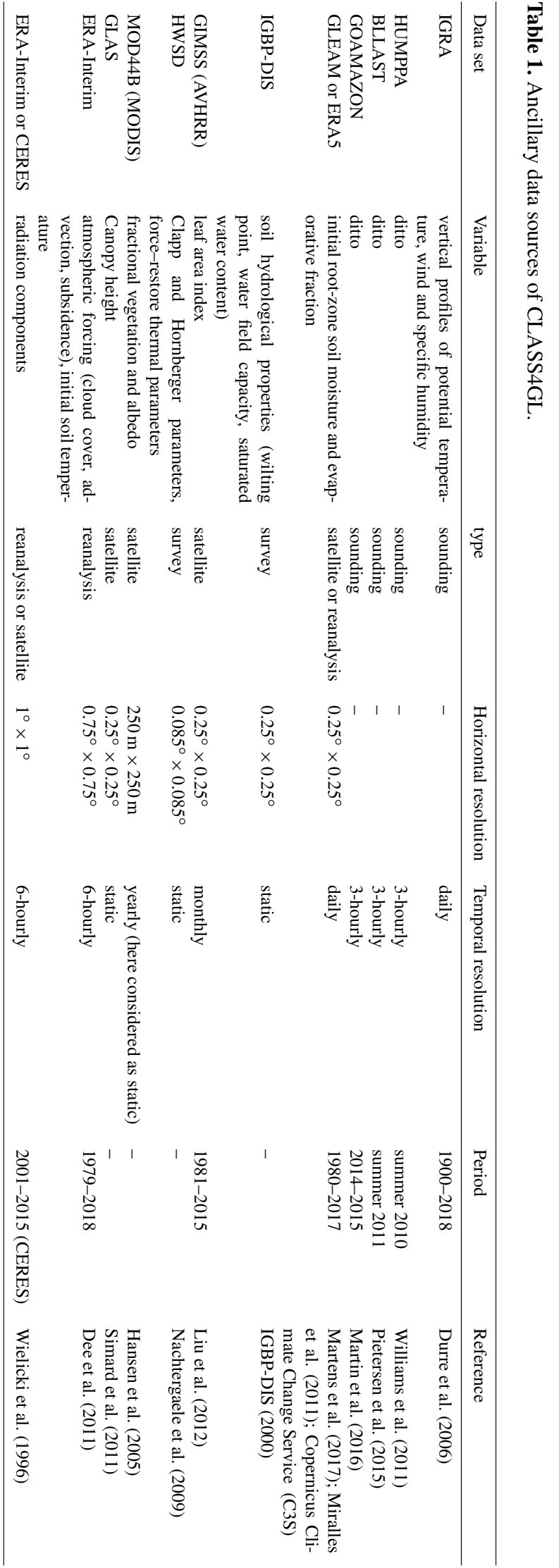

rameters. Other factors, like the underestimation of the entrainment may also contribute to the cold and wet bias of the model. Particularly, the modeled mixed-layer heat gain by entrainment is positive $\left(0.011 \mathrm{~K} \mathrm{~m} \mathrm{~s}^{-1}\right.$; i.e., warm air entrainment) and the average mixed-layer moisture gain by entrainment is negative $\left(-2.24 \times 10^{5} \mathrm{~kg} \mathrm{~kg}^{-1} \mathrm{~m} \mathrm{~s}^{-1}\right.$; i.e., dry air entrainment) averaged over the whole sounding database. Intuitively, if entrainment was increased, e.g., due to a higher entrainment velocity, it would lead to further warming (in terms of $\theta$ ) and drying (in terms of $q$ ) of the mixed layer; hence it would act to reduce the overall bias.

Overall, validation results in Figs. 3 and 4 show that CLASS4GL provides preprocessing and modeling tools that can be used to represent the overall diurnal behavior of the ABL. The model realistically represents the main characteristics of the global ABL diurnal evolution according to balloon soundings, including the observed variability around the globe. Several limitations are highlighted; when applying CLASS4GL, one should be aware of the fact that model parameters and assumptions, combined with input data uncertainty, can lead to the failure to simulate specific sounding profiles. The framework is in continuous development, and it is expected that results will improve with higher resolution and accuracy of the forcing datasets, and with evolving model concepts of the ABL and land-atmosphere interface. The use of local parameterizations and higher-quality forcing is encouraged for applications in specific regions.

\section{Conclusion and perspective}

We have presented a novel interactive data platform, referred to as CLASS4GL (http://class4gl.eu, last access: 27 May 2018), to automize the study of the diurnal ABL based on balloon radiosondes launched worldwide since the early 1980s. The framework (a) mines balloon sounding data to initialize and validate the ABL bulk model CLASS, (b) links to a predefined but expandable set of global datasets that are used to constrain the surface and large-scale atmospheric conditions in the CLASS simulations, (c) is successful in evaluating the skill to simulate the ABL globally, (d) provides a flexible and user-friendly interface for allowing extensive amount of experiments on supercomputer environments thanks to a low computational cost (e.g., a batch of 41000 diurnal simulations only takes $\sim 1 \mathrm{~h}$ on a contemporary supercomputer infrastructure), and (e) strives for a community-driven architecture that allows us to seamlessly share input datasets, experiments, analyses and model developments among the climate research community and that also facilitates hackathons, workshops and educational activities. Validation results show an overall realistic representation of the diurnal evolution of mixed-layer height, potential temperature and specific humidity, using data from three observation campaigns and the IGRA operational sounding dataset. 
Table 2. Main input parameters for CLASS4GL. The parameter specifications and source acronyms are explained in Sect. 2.3 and Table 1.

\begin{tabular}{|c|c|c|c|}
\hline \multicolumn{4}{|l|}{ Vegetation } \\
\hline Symbol & Name & Unit & Default value or source \\
\hline LAI & Leaf area index of vegetated surface fraction & $(-)$ & GIMSS (daily) \\
\hline$r_{\mathrm{c}, \min }$ & Minimum resistance transpiration & $\left(\mathrm{s} \mathrm{m}^{-1}\right)$ & 110 \\
\hline$r_{\mathrm{s}, \text { soil, } \min }$ & Minimum resistance soil evaporation & $\left(\mathrm{s} \mathrm{m}^{-1}\right)$ & 50 \\
\hline$g_{\mathrm{D}}$ & $\begin{array}{l}\text { Vapor pressure deficit correction factor for surface re- } \\
\text { sistance }\end{array}$ & $(-)$ & 0 \\
\hline$h_{\text {can }}$ & Canopy height & $(\mathrm{m})$ & GLAS (static) \\
\hline$z_{0 \mathrm{~m}}$ & Roughness length for momentum & $(\mathrm{m})$ & $0.1 \times h_{\text {can }}($ static $)$ \\
\hline$z_{0 \mathrm{~h}}$ & Roughness length for heat and moisture & $(\mathrm{m})$ & $0.1 \times z_{0 \mathrm{~m}}($ static $)$ \\
\hline$\alpha$ & Surface albedo & $(-)$ & MOD44B (static) \\
\hline$T_{\mathrm{S}}$ & Initial surface temperature & $(\mathrm{K})$ & ERA-Interim (3-hourly) \\
\hline$T_{\text {soil }, 1}, T_{\text {soil }, 2}$ & Initial temperature of the top and deep soil layer & $(\mathrm{K})$ & ERA-Interim (3-hourly) \\
\hline$\omega_{\text {sat }}$ & Saturated volumetric water content & $\left(\mathrm{m}^{3} \mathrm{~m}^{-3}\right)$ & IGBP-DIS (static) \\
\hline \multicolumn{4}{|l|}{ Soil } \\
\hline Symbol & Name & Unit & Default value or source \\
\hline$\omega_{\mathrm{fc}}$ & Volumetric water content field capacity & $\left(\mathrm{m}^{3} \mathrm{~m}^{-3}\right)$ & IGBP-DIS (static) \\
\hline$\omega_{\text {wilt }}$ & Volumetric water content wilting point & $\left(\mathrm{m}^{3} \mathrm{~m}^{-3}\right)$ & IGBP-DIS (static) \\
\hline $\mathrm{EF}$ & Evaporative fraction & $(-)$ & ERA5 (hourly) or GLEAM (daily) \\
\hline$\omega_{\text {soil }, 1}, \omega_{\text {soil }, 2}$ & Volumetric water content top and deep soil layer & $\left(\mathrm{m}^{3} \mathrm{~m}^{-3}\right)$ & By iterative matching of EF \\
\hline$c_{\mathrm{veg}}$ & Vegetation fraction & $(-)$ & MOD44B (static) \\
\hline$a, b, p$ & Clapp and Hornberger retention curve parameters & $(-)$ & HWSD (static) \\
\hline$C_{\text {Gsat }}$ & Saturated soil conductivity for heat & $\left(\mathrm{K} \mathrm{m}^{-2} \mathrm{~J}^{-1}\right)$ & HWSD (static) \\
\hline$C_{2, \text { sat }}$ & Coefficient force term moisture & $(-)$ & HWSD (static) \\
\hline$C_{2, \text { ref }}$ & Coefficient restore term moisture & $(-)$ & HWSD (static) \\
\hline$\Lambda$ & Thermal diffusivity skin layer & $(-)$ & 5.9 \\
\hline \multicolumn{4}{|l|}{ Air } \\
\hline Symbol & Name & Unit & Default value or source \\
\hline$\beta$ & $\begin{array}{l}\text { Ratio between buoyancy virtual heat and entrainment } \\
\text { virtual heat }\end{array}$ & $(-)$ & 0.2 \\
\hline$\gamma_{\theta}$ & $\begin{array}{l}\text { Initial lapse rate of potential temperature in the free } \\
\text { atmosphere }\end{array}$ & $\left(\mathrm{K} \mathrm{m}^{-1}\right)$ & From profile (IGRA) \\
\hline$\gamma_{q}$ & $\begin{array}{l}\text { Initial lapse rates of specific humidity in the free at- } \\
\text { mosphere }\end{array}$ & $\left(\mathrm{kg} \mathrm{kg}^{-1} \mathrm{~m}^{-1}\right)$ & Ditto \\
\hline$\gamma_{u}, \gamma_{v}$ & $\begin{array}{l}\text { Initial lapse rates of zonal and meridional compo- } \\
\text { nents in the free atmosphere }\end{array}$ & $\left(m^{-1}\right)$ & Ditto \\
\hline$\Delta \theta_{h}$ & $\begin{array}{l}\text { Initial jump for potential temperature between the } \\
\text { mixed layer and free atmosphere }\end{array}$ & $(\mathrm{K})$ & Ditto \\
\hline$\Delta \theta_{q}$ & $\begin{array}{l}\text { Initial jump for specific humidity between the mixed } \\
\text { layer and free atmosphere }\end{array}$ & $\left(\mathrm{kg} \mathrm{kg}^{-1}\right)$ & Ditto \\
\hline$\Delta \theta_{u}, \Delta \theta_{v}$ & $\begin{array}{l}\text { Initial jump for zonal and meridional wind compo- } \\
\text { nents between the mixed layer and free atmosphere }\end{array}$ & $\left(\mathrm{m} \mathrm{s}^{-1}\right)$ & Ditto \\
\hline$-\left\langle\overline{\boldsymbol{U}} \cdot \nabla_{\mathbf{h o r}} \bar{\theta}\right\rangle$ & Mixed-layer horizontal heat advection & $\left(\mathrm{Ks} \mathrm{s}^{-1}\right)$ & ERA-Interim (6-hourly) \\
\hline$-\left\langle\bar{U} \cdot \nabla_{\text {hor }} \bar{q}\right\rangle$ & Mixed-layer moisture advection & $\left(\mathrm{kg} \mathrm{kg}^{-1} \mathrm{~s}^{-1}\right)$ & ERA-Interim (6-hourly) \\
\hline$-\left\langle\overline{\boldsymbol{U}} \cdot \nabla_{\mathbf{h o r}} \bar{u}\right\rangle$ & Mixed-layer advection of zonal momentum & $\left(\mathrm{m} \mathrm{s}^{-2}\right)$ & ERA-Interim (6-hourly) \\
\hline$-\left\langle\overline{\boldsymbol{U}} \cdot \nabla_{\mathbf{h o r}} \bar{v}\right\rangle$ & Mixed-layer advection of meridional momentum & $\left(\mathrm{m} \mathrm{s}^{-2}\right)$ & ERA-Interim (6-hourly) \\
\hline$w_{h}$ & Subsidence & $\left(\mathrm{m} \mathrm{s}^{-1}\right)$ & ERA-Interim (6-hourly) \\
\hline
\end{tabular}


The freely available model framework offers new perspectives to foster the study of the diurnal evolution of the ABL and the associated land-atmosphere feedbacks:

- The fast software infrastructure allows any researcher to easily employ extensive global sensitivity experiments, in which both land and atmospheric parameters can be perturbed. That can be used to investigate the effect of land conditions and large-scale atmospheric forcing on the ABL evolution worldwide. Particularly, this initiative fits well within the context of LoCo activities (http: //www.gewex.org/loco/, last access: 27 May 2018), e.g., to construct mixing diagrams and other metrics to understand land-atmospheric feedbacks. Moreover, by integrating global information of precipitation, temperature and cloud statistics, one could further investigate whether particular combinations of surface and atmospheric conditions lead to ABL properties that favor or disfavor the occurrence of convection, clouds, precipitation or extreme temperatures.

- Using the radio sounding simulations as a reference, the framework can be employed to study the climate model representation of ABL dynamics and the associated land-atmosphere feedbacks at diurnal scales and to evaluate satellite-based products and reanalysis data. Such a process-based validation can help improve climate models and assess the quality of satellite products intended to monitor the land-atmosphere interface.

- It could be used to challenge the added value of including novel mechanistic concepts, such as the dynamic representation of soil and vegetation interacting with the carbon cycle $\left(\mathrm{CO}_{2}\right.$ exchange, carbon stock, air $\mathrm{CO}_{2}$ levels, etc.), atmospheric chemistry (volatile organic compounds, aerosols, ozone, etc.), vegetation dynamics and water stress (Combe et al., 2016), or urbanization (Droste et al., 2018; Wouters et al., 2016).

- Finally, the ABL evolution and the associated landatmosphere interactions could be extracted from climate projections and land-cover climate scenarios. This way, one may determine the local drivers of shifting (extreme) weather under climate change, hence providing a better process understanding. When integrating future land use scenarios, this may foster the development of more effective climate adaptation strategies, e.g., by quantifying the mitigatory potential of land use change that could alleviate the escalation of mixed-layer temperatures during heat waves.

Code availability. CLASS4GL is freely available as a Python module and is conveyed under GNU General Public license version 3 (GPLv3). The general information, code and tutorials for running the software are maintained at http://class4gl.eu (last access: 27 May 2018). The presented model version for CLASS4GL is 1.0.
All comments, questions, suggestions and criticism regarding the functioning of the Python routine can be directed to the author of this paper.

Author contributions. HW, DGM and IYP proposed the initial concept and data flow. HW developed the code and did the analyses. CCvH, JVGdA, AJT and JAS provided conceptual support regarding land-atmosphere interactions and ABL physics. HW and DGM led the writing with contributions from all coauthors. VM and IYP proposed improvements to the user interface. All authors contributed to the design of the experiments and the interpretation of the results.

Competing interests. The authors declare that they have no conflict of interest.

Acknowledgements. BLLAST field experiment was made possible thanks to the contributions of several institutions and other bodies: INSU-CNRS (Institute National des Sciences de 1'Univers, Centre National de la Recherche Scientifique, LEFE-IDAO program), Météo France, Observatoire Midi-Pyrénées (University of Toulouse), EUFAR (EUropean Facility for Airborne Research) and COST ES0802 (European Cooperation in the field of Science and Technology). The field experiment would not have occurred without the contribution of all participating European and American research groups, which have all contributed a significant amount (see http://bllast.sedoo.fr/supports/, last access: 27 May 2018). The BLLAST field experiment was hosted by the instrumental site of Centre des Recherches Atmosphérique, Lannemezan, France (Observatoire Midi-Pyrénées, Laboratoire d'Aérologie). BLLAST data are managed by SEDOO, from Observatoire Midi-Pirénées. We would like to express our gratitude for the campaign data contained in Williams et al. (2011) and Martin et al. (2016) for HUMPPA and GOAMAZON, respectively. We thank Florian Cochard and Pierre Gentine for the radiosonde and profile analysis. We also thank Dominik Schumacher and Joke De Meester for employing independent tests of the software code and tutorials, Brecht Martens for the support for the global input databases, and the two anonymous referees for their valuable suggestions. The computational resources and services used in this work were provided by the VSC (Flemish Supercomputer Center), funded by the Research Foundation, Flanders (FWO), and the Flemish Government, department EWI.

Financial support. This research was funded by the European Research Council (ERC) under grant agreement no. 715254 (DRY-2DRY).

Review statement. This paper was edited by David Topping and reviewed by two anonymous referees. 


\section{References}

Akkermans, T., Rompaey, A. V., Lipzig, N. V., Moonen, P., and Verbist, B.: Quantifying successional land cover after clearing of tropical rainforest along forest frontiers in the Congo Basin, Phys. Geogr., 34, 417-440, https://doi.org/10.1080/02723646.2013.855698, 2013.

Bauer, L. A.: The Relation between "Potential Temperature" and "Entropy", Phys. Rev., 26, 177-183, https://doi.org/10.1103/physrevseriesi.26.177,

Berg, A., Lintner, B. R., Findell, K., Seneviratne, S. I., van den Hurk, B., Ducharne, A., Chéruy, F., Hagemann, S., Lawrence, D. M., Malyshev, S., Meier, A., and Gentine, P.: Interannual Coupling between Summertime Surface Temperature and Precipitation over Land: Processes and Implications for Climate Change, J. Climate, 28, 1308-1328, https://doi.org/10.1175/jclid-14-00324.1, 2015.

Betts, A. K. and Ball, J. H.: The FIFE surface diurnal cycle climate, J. Geophys. Res., 100, 25679, https://doi.org/10.1029/94jd03121, 1995.

Burden, R. L., Faires, D. J., and Burden, A. M.: Numerical Analysis, 10th Edn., ISBN 13: 978-1305253667, ISBN 10: 1305253663 , Cengage Learning, Boston, 2016.

Clapp, R. B. and Hornberger, G. M.: Empirical equations for some soil hydraulic properties, Water Resour. Res., 14, 601-604, https://doi.org/10.1029/wr014i004p00601, 1978.

Combe, M., Vilà-Guerau de Arellano, J., Ouwersloot, H. G., and Peters, W.: Plant water-stress parameterization determines the strength of land-atmosphere coupling, Agr. Forest Meteorol., 217, 61-73, https://doi.org/10.1016/j.agrformet.2015.11.006, 2016.

Copernicus Climate Change Service (C3S): Fifth generation of ECMWF atmospheric reanalyses of the global climate, available at: https://cds.climate.copernicus.eu/cdsapp\#!/home (last access: 27 May 2019), 2017.

Davin, E. L., Rechid, D., Breil, M., Cardoso, R. M., Coppola, E., Hoffmann, P., Jach, L. L., Katragkou, E., de NobletDucoudré, N., Radtke, K., Raffa, M., Soares, P. M. M., Sofiadis, G., Strada, S., Strandberg, G., Tölle, M. H., WarrachSagi, K., and Wulfmeyer, V.: Biogeophysical impacts of forestation in Europe: First results from the LUCAS Regional Climate Model intercomparison, Earth Syst. Dynam. Discuss., https://doi.org/10.5194/esd-2019-4, in review, 2019.

Dee, D. P., Uppala, S. M., Simmons, A. J., Berrisford, P., Poli, P., Kobayashi, S., Andrae, U., Balmaseda, M. A., Balsamo, G., Bauer, P., Bechtold, P., Beljaars, A. C. M., van de Berg, L., Bidlot, J., Bormann, N., Delsol, C., Dragani, R., Fuentes, M., Geer, A. J., Haimberger, L., Healy, S. B., Hersbach, H., Hólm, E. V., Isaksen, L., Kållberg, P., Köhler, M., Matricardi, M., McNally, A. P., Monge-Sanz, B. M., Morcrette, J.-J., Park, B.-K., Peubey, C., de Rosnay, P., Tavolato, C., Thépaut, J.-N., and Vitart, F.: The ERA-Interim reanalysis: configuration and performance of the data assimilation system, Q. J. Roy. Meteor. Soc., 137, 553-597, https://doi.org/10.1002/qj.828, 2011.

Droste, A. M., Steeneveld, G. J., and Holtslag, A. A. M.: Introducing the urban wind island effect, Environ. Res. Lett., 13, 094007, https://doi.org/10.1088/1748-9326/aad8ef, 2018.

Durre, I., Vose, R. S., and Wuertz, D. B.: Overview of the Integrated Global Radiosonde Archive, J. Climate, 19, 53-68, https://doi.org/10.1175/jcli3594.1, 2006.
Ek, M. and Mahrt, L.: Daytime Evolution of Relative Humidity at the Boundary Layer Top, Mon. Weather Rev., 122, 2709-2721, https://doi.org/10.1175/15200493(1994)122<2709:deorha>2.0.co;2, 1994.

Findell, K. L., Gentine, P., Lintner, B. R., and Kerr, C.: Probability of afternoon precipitation in eastern United States and Mexico enhanced by high evaporation, Nat. Geosci., 4, 434-439, https://doi.org/10.1038/ngeo1174, 2011.

Fischer, E. M., Seneviratne, S. I., Lüthi, D., and Schär, C.: Contribution of land-atmosphere coupling to recent European summer heat waves, Geophys. Res. Lett., 34, L06707, https://doi.org/10.1029/2006g1029068, 2007.

Guillod, B. P., Orlowsky, B., Miralles, D. G., Teuling, A. J., and Seneviratne, S. I.: Reconciling spatial and temporal soil moisture effects on afternoon rainfall, Nat. Commun., 6, 6443, https://doi.org/10.1038/ncomms7443, 2015.

Guo, Z., Dirmeyer, P. A., Koster, R. D., Sud, Y. C., Bonan, G., Oleson, K. W., Chan, E., Verseghy, D., Cox, P., Gordon, C. T., McGregor, J. L., Kanae, S., Kowalczyk, E., Lawrence, D., Liu, P., Mocko, D., Lu, C.-H., Mitchell, K., Malyshev, S., McAvaney, B., Oki, T., Yamada, T., Pitman, A., Taylor, C. M., Vasic, R., and Xue, Y.: GLACE: The Global Land-Atmosphere Coupling Experiment. Part II: Analysis, J. Hydrometeorol., 7, 611-625, https://doi.org/10.1175/jhm511.1, 2006.

Hansen, M. C., Townshend, J. R. G., DeFries, R. S., and Carroll, M.: Estimation of tree cover using MODIS data at global, continental and regional/local scales, Int. J. Remote Sens., 26, 4359-4380, https://doi.org/10.1080/01431160500113435, 2005.

IGBP-DIS: Global gridded surfaces of selection soil characteristics (IGBP-DIS), https://doi.org/10.3334/ornldaac/569, 2000.

Jarvis, P. G.: The Interpretation of the Variations in Leaf Water Potential and Stomatal Conductance Found in Canopies in the Field, Philos. T. R. Soc. B, 273, 593-610, https://doi.org/10.1098/rstb.1976.0035, 1976.

Koster, R. D., Sud, Y. C., Guo, Z., Dirmeyer, P. A., Bonan, G., Oleson, K. W., Chan, E., Verseghy, D., Cox, P., Davies, H., Kowalczyk, E., Gordon, C. T., Kanae, S., Lawrence, D., Liu, P., Mocko, D., Lu, C.-H., Mitchell, K., Malyshev, S., McAvaney, B., Oki, T., Yamada, T., Pitman, A., Taylor, C. M., Vasic, R., and Xue, Y.: GLACE: The Global Land-Atmosphere Coupling Experiment. Part I: Overview, J. Hydrometeorol., 7, 590-610, https://doi.org/10.1175/jhm510.1, 2006.

Lawston, P. M., Santanello, J. A., Zaitchik, B. F., and Rodell, M.: Impact of Irrigation Methods on Land Surface Model Spinup and Initialization of WRF Forecasts, J. Hydrometeorol., 16, 11351154, https://doi.org/10.1175/jhm-d-14-0203.1, 2015.

Lejeune, Q., Davin, E. L., Guillod, B. P., and Seneviratne, S. I.: Influence of Amazonian deforestation on the future evolution of regional surface fluxes, circulation, surface temperature and precipitation, Clim. Dynam., 44, 2769-2786, https://doi.org/10.1007/s00382-014-2203-8, 2014.

Liu, Y., Liu, R., and Chen, J. M.: Retrospective retrieval of longterm consistent global leaf area index (1981-2011) from combined AVHRR and MODIS data, J. Geophys. Res.-Biogeo., 117, G04003, https://doi.org/10.1029/2012jg002084, 2012.

Martens, B., Miralles, D. G., Lievens, H., van der Schalie, R., de Jeu, R. A. M., Fernández-Prieto, D., Beck, H. E., Dorigo, W. A., and Verhoest, N. E. C.: GLEAM v3: satellite-based land evapora- 
tion and root-zone soil moisture, Geosci. Model Dev., 10, 19031925, https://doi.org/10.5194/gmd-10-1903-2017, 2017.

Martin, S. T., Artaxo, P., Machado, L. A. T., Manzi, A. O., Souza, R. A. F., Schumacher, C., Wang, J., Andreae, M. O., Barbosa, H. M. J., Fan, J., Fisch, G., Goldstein, A. H., Guenther, A., Jimenez, J. L., Pöschl, U., Silva Dias, M. A., Smith, J. N., and Wendisch, M.: Introduction: Observations and Modeling of the Green Ocean Amazon (GoAmazon2014/5), Atmos. Chem. Phys., 16, 47854797, https://doi.org/10.5194/acp-16-4785-2016, 2016.

Miralles, D. G., Holmes, T. R. H., De Jeu, R. A. M., Gash, J. H., Meesters, A. G. C. A., and Dolman, A. J.: Global land-surface evaporation estimated from satellite-based observations, Hydrol. Earth Syst. Sci., 15, 453-469, https://doi.org/10.5194/hess-15453-2011, 2011.

Miralles, D. G., Teuling, A. J., van Heerwaarden, C. C., and VilàGuerau de Arellano, J.: Mega-heatwave temperatures due to combined soil desiccation and atmospheric heat accumulation, Nat. Geosci., 7, 345-349, https://doi.org/10.1038/ngeo2141, 2014.

Miralles, D. G., Gentine, P., Seneviratne, S. I., and Teuling, A. J.: Land-atmospheric feedbacks during droughts and heatwaves: state of the science and current challenges, Ann. NY. Acad. Sci., 1436, 19-35, https://doi.org/10.1111/nyas.13912, 2018.

Monin, A. S. and Obukhov, A. M.: Basic laws of turbulent mixing in the surface layer of the atmosphere, Contributions of the Geophysical Institute of the Slovak Academy of Sciences, Contrib. Geophys. Inst. Acad. Sci. USSR, 24, 163-187, 1954.

Monteith, J. L.: Radiation and Crops, Exp. Agr., 1, 241, https://doi.org/10.1017/s0014479700021529, 1965.

Nachtergaele, F., van Velthuizen, H., Verelst, L., Batjes, N., Dijkshoorn, K., van Engelen, V., Fischer, G., Jones, A., Montanarella, L., Petri, M., Prieler, S., Teixeira, E., Wiberg, D., and Shi, X.: Harmonized World Soil Database, Tech. rep., Food and Agriculture Organization of the United Nations, 2009.

Noilhan, J. and Mahfouf, J.-F.: The ISBA land surface parameterisation scheme, Global Planet. Change, 13, 145-159, https://doi.org/10.1016/0921-8181(95)00043-7, 1996.

Noilhan, J. and Planton, S.: A Simple Parameterization of Land Surface Processes for Meteorological Models, Mon. Weather Review, 117, 536-549, https://doi.org/10.1175/15200493(1989)117<0536:aspols>2.0.co;2, 1989.

Orlowsky, B. and Seneviratne, S. I.: Statistical Analyses of LandAtmosphere Feedbacks and Their Possible Pitfalls, J. Climate, 23, 3918-3932, https://doi.org/10.1175/2010jcli3366.1, 2010.

Ouwersloot, H. G., Vilà-Guerau de Arellano, J., Nölscher, A. C., Krol, M. C., Ganzeveld, L. N., Breitenberger, C., Mammarella, I., Williams, J., and Lelieveld, J.: Characterization of a boreal convective boundary layer and its impact on atmospheric chemistry during HUMPPA-COPEC-2010, Atmos. Chem. Phys., 12, 9335-9353, https://doi.org/10.5194/acp-12-9335-2012, 2012.

Paulson, C. A.: The Mathematical Representation of Wind Speed and Temperature Profiles in the Unstable Atmospheric Surface Layer, J. Appl. Meteorol., $\quad 9, \quad 857-861, \quad$ https://doi.org/10.1175/15200450(1970)009<0857:tmrows>2.0.co;2, 1970.

Petrova, I., Miralles, D., van Heerwaarden, C., and Wouters, H.: Relation between Convective Rainfall Properties and Antecedent Soil Moisture Heterogeneity Conditions in North Africa, Remote Sens., 10, 969, https://doi.org/10.3390/rs10060969, 2018.
Pietersen, H. P., Vilà-Guerau de Arellano, J., Augustin, P., van de Boer, A., de Coster, O., Delbarre, H., Durand, P., Fourmentin, M., Gioli, B., Hartogensis, O., Lohou, F., Lothon, M., Ouwersloot, H. G., Pino, D., and Reuder, J.: Study of a prototypical convective boundary layer observed during BLLAST: contributions by large-scale forcings, Atmos. Chem. Phys., 15, 42414257, https://doi.org/10.5194/acp-15-4241-2015, 2015.

Ridder, K. D.: Bulk Transfer Relations for the Roughness Sublayer, Bound.-Lay. Meteorol., 134, 257-267, https://doi.org/10.1007/s10546-009-9450-y, 2009.

Roundy, J. K. and Santanello, J. A.: Utility of Satellite Remote Sensing for Land-Atmosphere Coupling and Drought Metrics, J. Hydrometeorol., 18, 863-877, https://doi.org/10.1175/jhm-d16-0171.1, 2017.

Roundy, J. K., Ferguson, C. R., and Wood, E. F.: Temporal Variability of Land-Atmosphere Coupling and Its Implications for Drought over the Southeast United States, J. Hydrometeorol., 14, 622-635, https://doi.org/10.1175/jhm-d-12-090.1, 2013.

Santanello, J. A., Peters-Lidard, C. D., Kumar, S. V., Alonge, C., and Tao, W.-K.: A Modeling and Observational Framework for Diagnosing Local Land-Atmosphere Coupling on Diurnal Time Scales, J. Hydrometeorol., 10, 577-599, https://doi.org/10.1175/2009jhm1066.1, 2009.

Santanello, J. A., Roundy, J., and Dirmeyer, P. A.: Quantifying the Land-Atmosphere Coupling Behavior in Modern Reanalysis Products over the U.S. Southern Great Plains, J. Climate, 28, 5813-5829, https://doi.org/10.1175/jcli-d-14-00680.1, 2015.

Santanello, J. A., Dirmeyer, P. A., Ferguson, C. R., Findell, K. L., Tawfik, A. B., Berg, A., Ek, M., Gentine, P., Guillod, B. P., van Heerwaarden, C., Roundy, J., and Wulfmeyer, V.: LandAtmosphere Interactions: The LoCo Perspective, B. Am. Meteorol. Soc., 99, 1253-1272, https://doi.org/10.1175/bams-d-170001.1, 2018.

Seneviratne, S. I., Corti, T., Davin, E. L., Hirschi, M., Jaeger, E. B., Lehner, I., Orlowsky, B., and Teuling, A. J.: Investigating soil moisture-climate interactions in a changing climate: A review, Earth-Sci. Rev., 99, 125-161, https://doi.org/10.1016/j.earscirev.2010.02.004, 2010.

Sillmann, J., Thorarinsdottir, T., Keenlyside, N., Schaller, N., Alexander, L. V., Hegerl, G., Seneviratne, S. I., Vautard, R., Zhang, X., and Zwiers, F. W.: Understanding, modeling and predicting weather and climate extremes: Challenges and opportunities, Weather and Climate Extremes, 18, 65-74, https://doi.org/10.1016/j.wace.2017.10.003, 2017.

Simard, M., Pinto, N., Fisher, J. B., and Baccini, A.: Mapping forest canopy height globally with spaceborne lidar, J. Geophys. Res., 116, G04021, https://doi.org/10.1029/2011jg001708, 2011.

Tawfik, A. B., Dirmeyer, P. A., and Santanello, J. A.: The Heated Condensation Framework. Part I: Description and Southern Great Plains Case Study, J. Hydrometeorol., 16, 1929-1945, https://doi.org/10.1175/jhm-d-14-0117.1, 2015.

Taylor, C. M., de Jeu, R. A. M., Guichard, F., Harris, P. P., and Dorigo, W. A.: Afternoon rain more likely over drier soils, Nature, 489, 423-426, https://doi.org/10.1038/nature11377, 2012.

Tennekes, H.: A Model for the Dynamics of the Inversion Above a Convective Boundary Layer, J. Atmos. Sci., 30, 558-567, https://doi.org/10.1175/15200469(1973)030<0558:amftdo>2.0.co;2, 1973. 
Tennekes, H. and Driedonks, A. G. M.: Basic entrainment equations for the atmospheric boundary layer, Bound.-Lay. Meteorol., 20, 515-531, https://doi.org/10.1007/bf00122299, 1981.

Teuling, A. J., Van Loon, A. F., Seneviratne, S. I., Lehner, I., Aubinet, M., Heinesch, B., Bernhofer, C., Grünwald, T., Prasse, H., and Spank, U.: Evapotranspiration amplifies European summer drought, Geophys. Res. Lett., 40, 2071-2075, https://doi.org/10.1002/grl.50495, 2013.

Thiery, W., Davin, E. L., Lawrence, D. M., Hirsch, A. L., Hauser, M., and Seneviratne, S. I.: Present-day irrigation mitigates heat extremes, J. Geophys. Res.-Atmos., 122, 1403-1422, https://doi.org/10.1002/2016jd025740, 2017.

van Heerwaarden, C. C. and Teuling, A. J.: Disentangling the response of forest and grassland energy exchange to heatwaves under idealized land-atmosphere coupling, Biogeosciences, 11, 6159-6171, https://doi.org/10.5194/bg-11-6159-2014, 2014.

van Heerwaarden, C. C., Vilà-Guerau de Arellano, J., Moene, A. F., and Holtslag, A. A. M.: Interactions between dryair entrainment, surface evaporation and convective boundarylayer development, Q. J. Roy. Meteor. Soc., 135, 1277-1291, https://doi.org/10.1002/qj.431, 2009.

van Heerwaarden, C. C., Vilà-Guerau de Arellano, J., Gounou, A., Guichard, F., and Couvreux, F.: Understanding the Daily Cycle of Evapotranspiration: A Method to Quantify the Influence of Forcings and Feedbacks, J. Hydrometeorol., 11, 1405-1422, https://doi.org/10.1175/2010jhm1272.1, 2010.

van Stratum, B. J. H. and Stevens, B.: The Impact of Vertical Mixing Biases in Large-Eddy Simulation on Nocturnal Low Clouds, J. Adv. Model. Earth Sy., 10, 1290-1303, https://doi.org/10.1029/2017ms001239, 2018.

Vilà-Guerau de Arellano, J., van Heerwaarden, C. C., and Lelieveld, J.: Modelled suppression of boundary-layer clouds by plants in a $\mathrm{CO}_{2}$-rich atmosphere, Nat. Geosci., 5, 701-704, https://doi.org/10.1038/ngeo1554, 2012.

Vilá-Guerau de Arellano, J., van Heerwaarden, C. C., van Stratum, B. J. H., and van den Dries, K.: The Atmospheric Boundary Layer, Cambridge University Press, 2015.

Wielicki, B. A., Barkstrom, B. R., Harrison, E. F., Lee, R. B., Louis Smith, G., Cooper, J. E., Wielicki, B. A., Barkstrom, B. R., Harrison, E. F., III, R. B. L., Smith, G. L., and Cooper, J. E.: Clouds and the Earth's Radiant Energy System (CERES): An Earth Observing System Experiment, B. Am. Meteorol. Soc., 77, 853-868, https://doi.org/10.1175/15200477(1996)077<0853:CATERE>2.0.CO;2, 1996.
Williams, J., Crowley, J., Fischer, H., Harder, H., Martinez, M., Petää, T., Rinne, J., Bäck, J., Boy, M., Dal Maso, M., Hakala, J., Kajos, M., Keronen, P., Rantala, P., Aalto, J., Aaltonen, H., Paatero, J., Vesala, T., Hakola, H., Levula, J., Pohja, T., Herrmann, F., Auld, J., Mesarchaki, E., Song, W., Yassaa, N., Nölscher, A., Johnson, A. M., Custer, T., Sinha, V., Thieser, J., Pouvesle, N., Taraborrelli, D., Tang, M. J., Bozem, H., Hosaynali-Beygi, Z., Axinte, R., Oswald, R., Novelli, A., Kubistin, D., Hens, K., Javed, U., Trawny, K., Breitenberger, C., Hidalgo, P. J., Ebben, C. J., Geiger, F. M., Corrigan, A. L., Russell, L. M., Ouwersloot, H. G., Vilà-Guerau de Arellano, J., Ganzeveld, L., Vogel, A., Beck, M., Bayerle, A., Kampf, C. J., Bertelmann, M., Köllner, F., Hoffmann, T., Valverde, J., González, D., Riekkola, M.-L., Kulmala, M., and Lelieveld, J.: The summertime Boreal forest field measurement intensive (HUMPPA-COPEC-2010): an overview of meteorological and chemical influences, Atmos. Chem. Phys., 11, 10599-10618, https://doi.org/10.5194/acp-11-10599-2011, 2011.

Wouters, H., Ridder, K. D., and van Lipzig, N. P. M.: Comprehensive Parametrization of Surface-Layer Transfer Coefficients for Use in Atmospheric Numerical Models, Bound.-Lay. Meteoro., 145, 539-550, https://doi.org/10.1007/s10546-012-9744-3, 2012.

Wouters, H., Demuzere, M., Blahak, U., Fortuniak, K., Maiheu, B., Camps, J., Tielemans, D., and van Lipzig, N. P. M.: The efficient urban canopy dependency parametrization (SURY) v1.0 for atmospheric modelling: description and application with the COSMO-CLM model for a Belgian summer, Geosci. Model Dev., 9, 3027-3054, https://doi.org/10.5194/gmd-9-3027-2016, 2016.

Wouters, H., De Ridder, K., Poelmans, L., Willems, P., Brouwers, J., Hosseinzadehtalaei, P., Tabari, H., Vanden Broucke, S., van Lipzig, N. P. M., and Demuzere, M.: Heat stress increase under climate change twice as large in cities as in rural areas: A study for a densely populated midlatitude maritime region, Geophy. Res. Lett., 44, 8997-9007, https://doi.org/10.1002/2017gl074889, 2017.

Zaitchik, B. F., Santanello, J. A., Kumar, S. V., and PetersLidard, C. D.: Representation of Soil Moisture Feedbacks during Drought in NASA Unified WRF (NU-WRF), J. Hydrometeorol., 14, 360-367, https://doi.org/10.1175/jhm-d-12-069.1, 2013.

Zhang, Y., Gao, Z., Li, D., Li, Y., Zhang, N., Zhao, X., and Chen, J.: On the computation of planetary boundary-layer height using the bulk Richardson number method, Geosci. Model Dev., 7, 2599 2611, https://doi.org/10.5194/gmd-7-2599-2014, 2014. 